\title{
Pengaruh Bermain Slime terhadap Rentang Sendi Phalang Pasien Stroke di Rumah Sakit Adi Husada Surabaya
}

\author{
Rina Budi Kristiani ${ }^{1}$, Chindy Maria Orizani ${ }^{2}$, Susanti Susanti ${ }^{3}$ \\ Sekolah Tinggi Ilmu Kesehatan Adi Husada ${ }^{1,2,3}$ \\ rinabudikristiani.rb@gmail.com ${ }^{1}$
}

\begin{abstract}
Diajukan 10 September 2019 Diperbaiki 10 September 2019 Diterima 20 November 2019
ABSTRAK

Latar Belakang: Pasien yang menderita stroke secara mendadak akan mengalami kelemahan ekstremitas, gangguan ini dapat mengganggu kegiatan hidup sehari-hari, tindakan yang dapat dilakukan perawat adalah melakukan range of motion yang menyenangkan dengan menggunakan bermain slime.

Tujuan: Penelitian ini bertujuan untuk mengetahui pengaruh bermain slime terhadap rentang sendi phalang pasien stroke di RS Adi Husada Surabaya.

Metode: Metode penelitian yang digunakan adalah quasi eksperimental dengan pre dan postt test di RS Adi Husada Surabaya selama April - Juli 2019 berjumlah 40 responden. Pengambilan sampel dilakukan dengan cara consecutive sampling, kelompok intervensi berjumlah 20 responden dan kelompok kontrol berjumlah 20 responden. Variabel independen dalam penelitian ini adalah Bermain Slime dan variabel dependennya adalah rentang sendi phalang. Instrumen yang digunakan dalam pengumpulan data

adalah lembar observasi untuk rentang sendi phalang yang diukur dengan menggunakan geniometer.

Hasil: Jenis kelamin laki-laki 67,5\%, kelompok umur dewasa dengan rentang usia 21-60 tahun sebanyak $57,5 \%$, serangan stroke sekali sebanyak $82,5 \%$ dan tidak ada dukungan keluarga sebesar 52,5\%. Hasil uji beda peningkatan rentang sendi sebelum dan sesudah intervensi pada kelompok intervensi $\left(18,29^{\circ}\right)$ dan kelompok kontrol $\left(3,23^{\circ}\right)$, statistik berbeda signifikan (t-independent test pralue $=0,020)$. Hasil Uji perbedaan rentang sendi pada kelompok intervensi sebelum intervensi $\left(33,02^{\circ}\right)$ dan sesudah intervensi $\left(51,31^{\circ}\right)$ statistik berbeda signifikan ( $t$-paired test pvalue $=0,003$ ).

Kesimpulan: Terdapat pengaruh antara Bermain Slime terhadap rentang sendi phalang pada pasien stroke karena bermain slime membantu melakukan latihan rentang gerak sendi phalang pada pasien stroke yang mengalami kelemahan rentang sendi phalang
\end{abstract}

Kata Kunci: stroke; bermain slime; rentang sendi phalang

\section{ABSTRACT}

Background: Patients suffering from a sudden stroke will experience limb weakness, this disorder can interfere with daily living activities, actions that can be performed by nurses are doing range of motion using a computer games that is fun.

Objective: The purpose of this research is knowing the influence of playing slime on phalang joint range of stroke patients in Adi Husada Hospital Surabaya.

Methods: The research method was quasi experimental with pre and post test design in Adi Husada Hospital Surabaya during April-July, 2019 with a number of 40 respondents. Sampling was done by consecutive sampling, respondents in the intervention group amounted to 20 respondents and respondents in the control group was 20. Variables independent in this study is Playing Slime and the variables dependent is phalanx joint range. The instrument used in the collection of data is an observation to phalanx joint range and measured with geniometer.
Result: Distribution characteristics for the majority of respondents, the male sex of 67,5\%, adult age group 21-60 years $57,5 \%$, Frequency of stroke in a one time group is $82,5 \%$ and the group of no family support amounted to $52,5 \%$. Difference test results on improving joint range before and after intervention in the intervention group $\left(18,29^{\circ}\right)$ and in the control groups $\left(3,23^{\circ}\right)$, statistically significantly different ( $t$-independent test pvalue $=0,020$ ). Difference test results on improving of joints in the intervention group before the intervention $33,02^{\circ}$ ) and after intervention $\left(51,31^{\circ}\right)$ statistically significant different (paired $t$-test pvalue $=0,003$ ).

Conclusion: There is influence between playing slime on phalang joint range of stroke patients because playing slime as a means to help perform range of motion exercises phalanx in stroke patients who experienced weakness phalanx joint range.

Keywords: stroke, playing slime, phalanx joint range 


\section{PENDAHULUAN}

Penurunan fungsi gerak pada tangan sering terjadi setelah stroke, hal ini didukung oleh (Rand, D., Zeilig, G., \& Kinozy, R., 2015) bahwa kelemahan ekstremitas atas paling umum terjadi pada pasien post stroke dan sebagian besar pasien mengalami gangguan fungsi pada tangan. Menurut (Sabini, R., C., 2013) menyatakan bahwa hemiparese adalah gangguan gerak yang sering dialami pasien setelah stroke dan sering mengakibatkan gangguan fungsi pada tangan. Selain itu menurut (Chen, M., H., 2015) menunjukkan penurunan anggota gerak atas merupakan salah satu tanda dari stroke. Menurut (Stroke Association, 2013) menyatakan bahwa stroke dapat terjadi pada dewasa muda yaitu sebanyak $25 \%$, antara $40 \%$ - 50\% stroke pada dewasa muda disebabkan oleh perdarahan. Kejadian stroke akan meningkat dengan bertambahnya usia dan akan meningkat dua kali lipat pada usia diatas 55 tahun dan dua pertiga kejadian stroke di atas usia 65 tahun.

Pasien stroke yang menjalani rawat inap di RS Adi Husada Surabaya sebanyak 642 pasien pada tahun 2017. Pasien stroke yang mengalami gangguan rentang gerak sendi ekstremitas atas pada tahun 2019 sebanyak 40 pasien dalam 1 bulan. Pasien yang sedang menjalani rawat inap di RS Adi Husada Surabaya mendapatkan latihan rentang gerak sendi oleh tenaga fisioterapi tetapi tidak semua pasien melanjutkan latihan secara mandiri.

Latihan yang dapat diaplikasikan untuk mengurangi tingkat tergantung dan mencegah kecacatan yang dialami pasien, perawat perlu melakukan rehabilitasi dini terhadap pasien post stroke dengan melakukan latihan range of motion (ROM). ROM adalah rentang gerak yaitu pergerakan sendi terjauh secara lengkap yang mampu dilakukan secara normal. ROM dapat dilakukan dengan melakukan latihan rentang gerak aktif, aktif dengan bantuan, atau pasif. Latihan tersebut harus dilakukan secara teratur. Latihan aktif dan pasif meningkatkan mobilitas sendi dan meningkatkan sirkulasi ke bagian yang sakit.
Latihan aktif meningkatkan fungsi jantung dan pernapasan. Latihan aktif harus memperhatikan kondisi fisik pasien.

Menurut(Chen, M., H., 2015; Perry, J., C., 2011) penggunaan permainan slime dapat meningkatkan motivasi dan partisipasi pasien untuk melakukan latihan ROM secara rutin dan mengurangi kebosanan karena melakukan kegiatan monoton, dengan pelaksanaan ROM yang terjadual akan membantu meningkatkan fungsi ekstremitas. Perawat bersama dengan pasien dan keluarga memodifikasi media yang dapat digunakan pasien untuk melakukan latihan ROM secara mandiri dan menyenangkan yaitu bermain slime. Bila hal ini dapat dilakukan proses rehabilitasi pada pasien yang mengalami gangguan rentang gerak sendi akan segera teratasi dan pasien dapat melakukan aktivitas hidup sehari-hari secara mandiri.

Tujuan dari penelitian ini adalah mengidentifikasi pengaruh bermain slime terhadap rentang sendi phalang pasien stroke.

\section{METODE}

Penelitian ini menggunakan jenis penelitian quasi eksperimen non equivalent pre-post test with control group di Rumah Sakit Adi Husada Surabaya selama April - Juli 2019 berjumlah 40 responden. Pengambilan sampel dilakukan dengan cara consecutive sampling, dibagi menjadi kelompok intervensi berjumlah 20 responden dan kelompok kontrol berjumlah 20 responden. Pada awal penelitian dilakukan pengukuran rentang sendi phalang pada kedua kelompok. Selanjutnya kelompok intervensi dilakukan bermain slime dengan durasi 30 menit selama 5 hari/minggu selama 4 minggu, dan pada akhir minggu ke 4 dilakukan pengukuran rentang sendi phalang kembali pada kedua kelompok. Analisa data bivariat menggunakan uji independent- $t$ test, dan paired-t test.

\section{HASIL}

A. Data umum

1. Jenis Kelamin 
Tabel 1. Distrubusi Frekuensi Responden Berdasarkan Jenis Kelamin

\begin{tabular}{lcccccc}
\hline \multicolumn{1}{c}{ Jenis } & \multicolumn{2}{c}{ Kelompok } & \multicolumn{2}{c}{ Kelompok } & \multicolumn{2}{c}{ Total } \\
kelamin & \multicolumn{2}{c}{ Kontrol } & \multicolumn{2}{c}{ Intervensi } & & \\
& $\mathrm{N}$ & $\%$ & $\mathrm{~N}$ & $\%$ & $\mathrm{~N}$ & $\%$ \\
\hline Laki-laki & 14 & 70 & 13 & 65 & 27 & 67,5 \\
Perempuan & 6 & 30 & 7 & 35 & 13 & 32,5 \\
\hline Jumlah & 20 & 100 & 20 & 100 & 40 & 100 \\
\hline
\end{tabular}

Tabel 1 menunjukkan sebagian besar responden yang berpartisipasi dalam penelitian ini berjenis kelamin laki-laki pada kelompok kontrol 14 orang (70\%) dan 13 orang (65\%) pada kelompok intervensi. Laki-laki lebih mudah mengalami stroke dibandingkan wanita karena wanita memiliki estrogen yang melindungi wanita terhadap kejadian stroke iskemik. Efek positif dari estrogen pada sirkulasi darah otak dapat melindungi wanita dari stroke iskemik, efek ini berhenti saat menopause (Appelros, P., Stegmayr, B., Terent, A., 2009).

2. Umur

Tabel 2. Distribusi Frekuensi Responden Berdasarkan Umur

\begin{tabular}{lcccccc}
\hline Umur & \multicolumn{2}{c}{ Kelompok } & \multicolumn{2}{c}{ Kelompok } & \multicolumn{2}{l}{ Total } \\
& \multicolumn{2}{c}{ Kontrol } & \multicolumn{2}{c}{ Intervensi } & & \\
& $\mathrm{N}$ & $\%$ & $\mathrm{~N}$ & $\%$ & $\mathrm{~N}$ & $\%$ \\
\hline 21-60 th & 11 & 55 & 12 & 60 & 23 & 57,5 \\
$>60$ th & 9 & 45 & 8 & 40 & 17 & 42,5 \\
\hline Jumlah & 20 & 100 & 20 & 100 & 40 & 100 \\
\hline
\end{tabular}

Tabel 2 menunjukkan sebagian besar responden yang berpartisipasi dalam penelitian ini berada pada kelompok umur dewasa yaitu 21-60 tahun sebanyak 11 orang (55\%) pada kelompok kontrol dan sebanyak 12 orang $(60 \%)$ pada kelompok intervensi. Stroke terjadi pada usia dewasa dan akan meningkat dengan bertambahnya usia (Stroke Association, 2013).

\section{Serangan Stroke}

Tabel 3. Distribusi Distrubusi Frekuensi Responden Berdasarkan Serangan Stroke

\begin{tabular}{lcccccc}
\hline \multirow{2}{*}{$\begin{array}{c}\text { Serangan } \\
\text { Stroke }\end{array}$} & \multicolumn{2}{c}{ Kelompok } & \multicolumn{2}{c}{ Kelompok } & \multicolumn{2}{c}{ Total } \\
& Kontrol & \multicolumn{2}{c}{ Intervensi } & & \\
& $\mathrm{N}$ & $\%$ & $\mathrm{~N}$ & $\%$ & $\mathrm{~N}$ & $\%$ \\
\hline 1 kali & 16 & 80 & 17 & 85 & 33 & 82,5 \\
2 kali & 3 & 15 & 2 & 10 & 5 & 12,5 \\
3 kali & 1 & 5 & 1 & 5 & 2 & 5 \\
\hline Jumlah & 20 & 100 & 20 & 100 & 40 & 100 \\
\hline
\end{tabular}

Tabel 3 menunjukkan sebagian besar responden yang berpartisipasi dalam penelitian ini mengalami serangan stroke sekali yaitu 16 orang (80\%) pada kelompok kontrol dan sebanyak 17 orang ( $85 \%$ ) pada kelompok intervensi. Stroke berulang dapat dicegah dengan melakukan perawatan segera saat pertama kali terkena serangan stroke kemudian dilanjutkan dengan perawatan jangka panjang (Laloux, 2010).

\section{Dukungan Keluarga}

Tabel 4. Distribusi Frekuensi Responden Berdasarkan Dukungan Keluarga

\begin{tabular}{lcccccc}
\hline Dukungan & \multicolumn{2}{c}{ Kelompok } & \multicolumn{2}{c}{ Kelompok } & \multicolumn{2}{c}{ Total } \\
Keluarga & \multicolumn{2}{c}{ Kontrol } & \multicolumn{2}{c}{ Intervensi } & & \\
& $\mathrm{N}$ & $\%$ & $\mathrm{~N}$ & $\%$ & $\mathrm{~N}$ & $\%$ \\
\hline Ada & 11 & 55 & 8 & 40 & 19 & 47,5 \\
Tidak Ada & 9 & 45 & 12 & 60 & 21 & 52,5 \\
\hline Jumlah & 20 & 100 & 20 & 100 & 40 & 100 \\
\hline
\end{tabular}

Tabel 4 menunjukkan sebagian besar responden yang berpartisipasi dalam penelitian ini mendapat dukungan keluarga pada kelompok kontrol yaitu sebanyak 11 orang $(55 \%)$ dan pada kelompok intervensi tidak mendapat dukungan keluarga yaitu 12 orang $(60 \%)$. Keluarga akan memberikan dukungan dalam perawatan, seiring bertambahnya tahun dukungan keluarga akan menurun (Urimubenshi \& Rhoda, 2011).

\section{B. Data khusus}

\section{Analisis Independent-t test}

Tabel 5. Perbedaan Rentang Sendi Phalang Pasien Stroke Sesudah Intervensi pada Kelompok Kontrol dan Intervensi

\begin{tabular}{ccccc}
\hline Variabel & Kelompok & N & Mean & $p$ value \\
\hline Rentang & Kontrol & 20 & 41,38 & \\
Sendi & Intervensi & 20 & 51,31 & 0,020 \\
Post & & & & \\
\hline
\end{tabular}

Tabel 5 menunjukkan terdapat perbedaan rentang sendi phalang antara kelompok intervensi dan kelompok kontrol sesudah intervensi dengan $p$ value 0.020 $(\alpha<0.05)$. 


\section{Analisis Paired-ttest}

Tabel 6. Perbedaan Derajat Rentang Sendi Phalang Pasien Stroke Sebelum dan Sesudah Intervensi Pada Kelompok Kontrol dan Intervensi

\begin{tabular}{cccc}
\hline Kelompok & \multicolumn{2}{c}{ Mean } & $p$ value \\
& Pre & Post & \\
\hline Kontrol & 38,15 & 41,38 & 0,000 \\
Intervensi & 33,02 & 51,31 & 0,003 \\
\hline
\end{tabular}

Tabel 6 didapatkan hasil yang signifikan terhadap rentang sendi phalang sebelum dan sesudah intervensi baik pada kelompok kontrol maupun kelompok intervensi dengan $p$ value kelompok kontrol 0,000 dan $p$ value kelompok intervensi 0,003 $(\alpha<0.05)$.

Tabel 7. Perbedaan Derajat Rentang Sendi Phalang Pasien Stroke Sesudah Intervensi Pada Kelompok Kontrol dan Intervensi

\begin{tabular}{cccc}
\hline $\begin{array}{c}\text { Rentang } \\
\text { Sendi }\end{array}$ & Kontrol & Intervensi & $p$ value \\
\hline Pre & 38,15 & 33,02 & 0,253 \\
Post & 41,38 & 51,31 & 0,020 \\
Peningkatan & 3,23 & 18,29 & 0,000 \\
\hline
\end{tabular}

Tabel 7 menunjukkan bahwa terjadi peningkatan derajat rentang sendi phalang pada kelompok intervensi setelah mendapatkan latihan bermain slime sebesar $18,29^{\circ}$. Hal ini menunjukkan terjadi peningkatan lebih besar pada rentang sendi phalang pada kelompok intervensi dibandingkan kelompok kontrol.

\section{PEMBAHASAN}

Hasil penelitian dimana pasien stroke yang mengalami keterbatasan motorik setelah diberikan latihan bermain slime terhadap sendi phalang menunjukkan perbedaan signifikan pada kelompok intervensi. Hasil tersebut diatas sesuai dengan penelitian yang dilakukan (Carabeo, C., G., Dalida, C., M., Padilla, E., M., \& Rodrigo, M., 2014) yang menyatakan setelah dua minggu menjalani latihan dengan menggunakan bermain slime, gerakan tangan pasien menunjukkan perbaikan. Selain itu menurut (Chen, M., H., 2015; Perry, I., C., 2011) menyatakan bahwa bermain slime dapat meningkatkan motivasi dan partisipasi pasien untuk melakukan latihan rentang $\mathrm{ROM}$ secara rutin dan mengurangi kebosanan, sehingga dapat meningkatkan fungsi ekstremitas. Hal ini menunjukkan bahwa bermain slime dapat digunakan sebagai sarana terapi untuk membantu untuk pasien stroke dengan kelemahan tangan. Latihan dengan bermain slime secara rutin akan meningkatkan kemampuan rentang gerak sendi. Latihan secara mandiri akan meningkatkan self care agency untuk memenuhi tuntutan kebutuhan hidup sehari-hari. Peran dari nursing agency juga menentukan keberhasilan dari pemulihan rentang sendi pasien stroke, tindakan yang dapat dilakukan perawat adalah mendampingi dan memberikan arahan pada pasien saat melakukan latihan rentang gerak dengan menggunakan media alternatif seperti bermain slime.

Pasien stroke yang mengalami kelemahan ekstremitas atas berusaha memenuhi perawatan dirinya (selfcare), dengan keterbatasan yang dimiliki tersebut, pasien stroke tidak mampu memenuhi seluruh kebutuhan perawatan dirinya secara mandiri (self-care deficit). Ketidakmampuan penderita dalam melakukan perawatan diri (self - care agent) dalam melakukan aktivitas secara mandiri (self care demand). Disinilah diperlukannya peran perawat dalam memenuhi kebutuhan perawatan bagi pasien stroke yang dapat tergambar dari nursing system Orem, dimana dibutuhkan asuhan keperawatan yang dilakukan perawat untuk menggunakan nursing agency dalam membantu penderita yang mengalami defisit perawatan diri. Dalam teorinya, Orem menekankan bahwa kebutuhan self-care dari individu dapat dipenuhi oleh perawat, individu atau oleh keduanya(Laloux, 2010).

Dalam melakukan tindakan keperawatan peneliti mengajarkan kepada pasien atau responden juga keluarga dan orang yang terlibat dalam membantu latihan rentang sendi phalang tentang cara menggunakan bermain slime untuk membantu melatih pergerakan sendi phalang dengan permainan 
yang dapat diperoleh dengan cara yang mudah dan menyenangkan. Disinilah peran perawat sebagai fasilitator membantu pasien yang mengalami defisit perawatan diri dalam memandirikan baik pasien, keluarga dan orang lain yang ikut merawat sehingga pasien atau keluarga dapat menggunakan dirinya sendiri sebaik mungkin dalam usaha perawatan dirinya. Berdasarkan hasil penelitian dan studiliteraturmenunjukkan bahwa um ur, jenis kelamin dan serangan stroke tidak mempengaruhi rentang sendi pasien stroke. Terdapat faktor lain yang perlu diteliti yang dapat mempengaruhi rentang sendi pada pada pasien stroke (Sabini, R., C., 2013).

Faktor lain yang terdapat baik dari dalam maupun dari luar individu dapat mempengaruhi self care agency pasien stroke dalam menghadapi dan menjalani proses pemulihan terhadap keterbatasan rentang sendi phalang. Bila faktor tersebut dapat digunakan secara maksimal, maka pemulihan rentang sendi phalang pada 3-6 bulan pertama post stroke.

\section{KESIMPULAN DAN SARAN}

Bermain slime sebagai sarana untuk membantu melakukan latihan rentang gerak sendiphalang pada pasien stroke yang mengalami kelemahan rentang sendi phalang.

\section{DAFTAR PUSTAKA}

Appelros, P., Stegmayr, B., Terent, A. (2009). Sex Differences in Stroke Epidemiology. Journal of The American Heart Association, 9. Carabeo, C., G., Dalida, C., M., Padilla, E., M., \& Rodrigo, M., T. (2014). Stroke Patient Rehabilitation : A Pilot Study of an Android-Based Game. Simulation \& Gaming, 151-166.

Chen, M., H. (2015). A Controlled Pilot Trial ofTwo Commercial Playing Slime for Rehabilitation of Arm Function After Stroke. Clinical Rehabilitation, 674-682.

Laloux, L. \& J. (2010). Risk Factors and Treatment of Stroke at The Time of Reccurence. Acta Neurology, 4.
Perry, J., C. (2011). Effective Game Use in Neurorehabilitation. Fatronik FoundationTECNALIA, 1-44.

Rand, D., Zeilig, G., \& Kinozy, R. (2015). Rehablet: Palying Slime for Self Training Impaired Dexterity Post Stroke: Study Protocol for A Pilot Randomized Controlled Trial. Biomed Central, 1-7.

Sabini, R., C. (2013). Stroke Survivors Talk While Doing: Development of A Therapeutik Framework for Continued Rehabilitation of Hand Function Post Stroke. Journal of Hand Therapy, 124-131.

Stroke Association. (2013). Stroke Statistics. Stroke, 1-13.

Urimubenshi \& Rhoda. (2011). Enviromentals Barriers Experienced by Stroke Patients in Muzanse District in Rwanda: A Descriptive Qualitative Study. African Health Sciences, 9 